\title{
Familial aggregation of malignant tumors in patients with pancreatic cancer: Findings from the Ragusa Cancer Registry (Sicily)
}

\author{
Martorana Caterina*1, Tumino Rosario ${ }^{1,2}$, Ponz de Leon Maurizio ${ }^{3}$ \\ ${ }^{1}$ Cancer Registry, Department of Medical Prevention, ASP Ragusa, Italy \\ ${ }^{2}$ Histopathology Unit, “Civic-M.P.Arezzo" Hospital, Ragusa, Italy \\ ${ }^{3}$ Unit of Internal Medicine, Department of Clinical and Diagnostic Medicine and Public Health, University of Modena and \\ Reggio Emilia, Italy
}

Received: July 15,2015

DOI: $10.5430 /$ jer.v2n2p65
Accepted: February 17, $2016 \quad$ Online Published: February 27, 2016

URL: http://dx.doi.org/10.5430/jer.v2n2p65

\begin{abstract}
Background and aims: Pancreatic cancer usually appears as a sporadic neoplasm, but there is increasing evidence that familial and hereditary factors may be involved in its pathogenesis. Using data from the population-based Ragusa Cancer Registry, we analyzed trends in the incidence of pancreatic cancer, as well as the presence and type of familial aggregation of tumors in pancreatic cancer patients.

Methods: The incidence of pancreatic cancer in Ragusa Province was taken from the local cancer registry for 1981-2009, and trends were analyzed. 142 of the 384 cases of pancreatic cancer diagnosed in 2000-2007 (37\%, 84 men, 58 women) were used for analyses of familial aggregation. Pancreatic cancer patients or their relatives were traced, contacted, and interviewed. The resultant information was used to compile a family history of disease, especially cancer, using our original pancreatic cancer patients as probands. Based on these family histories of disease, probands were divided into four categories: sporadic, simple familial aggregation, aspecific verticality, and site-specific verticality. Analyses of familial aggregation and survival were then carried out by presence (sporadic $v$ s. familial cases) and type of familial aggregation (i.e., simple familial aggregation vs. aspecific and site-specific verticality).

Results: The incidence of pancreatic cancer increased gradually in 1981-2009 in both sexes. No familial aggregation was observed for 47 of the probands (sporadic cases), whereas the remaining 95 (67\%) probands showed a more or less marked familial aggregation. Simple familial aggregation was observed in 43 of the probands, aspecific verticality in 49 , and site-specific verticality in 3 probands. Cancer of the breast (43 cases, $16.5 \%$ of the total), central nervous system, stomach, and colon-rectum were most frequently reported among relatives of probands. Survival analysis showed the usual poor prognosis of pancreatic cancer across all probands, regardless of presence or type of familial aggregation. Probands with familial aggregation did not differ from those with sporadic pancreatic cancer regarding stage of the disease, histological type, observed survival, or frequency of multiple tumors.

Conclusions: Pancreatic cancer patients showed a striking familial aggregation of malignant tumors, especially for cancer of the breast. Our attempt to classify probands by presence and type of familial aggregation might contribute relevant clues to the identification of inherited syndromes involving the pancreas. The marked association with breast cancer may suggest the involvement of BRCA1 and 2 gene mutations in the pathogenesis of some clusters of pancreatic cancer.
\end{abstract}

Key Words: Cancer, Familial aggregation, Incidence, Pancreas, Survival, Tumor

\footnotetext{
*Correspondence: Martorana Caterina; Email: martora.regtumragusa@tiscali.it; Address: Cancer Registry, Department of Medical Prevention, ASP Ragusa, Italy.
} 


\section{INTRODUCTION}

Pancreatic cancer is one of the major challenges facing the Western world due to its very aggressive clinical course, the difficulty of early diagnosis, treatment resistance, poor knowledge of its biological basis, and lack of prevention strategy. ${ }^{[1,2]}$ Survival among pancreatic cancer patients has changed very little in the last 20 to 30 years, with median survival in the order of 6 to 10 months and 5-year survival at less than $5 \% \cdot{ }^{[3,4]}$ Moreover, incidence rates are gradually increasing in both sexes in most European and American countries, including Italy. ${ }^{[5,6]}$

The great majority of pancreatic neoplasms are sporadic cases; however, there is growing evidence that familial aggregation of malignant tumors is present in a consistent portion of pancreatic cancer patients. ${ }^{[7]}$ In addition, recent studies have suggested that, at least in some cases, pancreatic cancer is associated with germline mutations of specific genes. ${ }^{[8,9]}$ The familial aggregation of tumors may be due to some unknown environmental agent that family members have in common; but the search for such agents in breast and colorectal cancer has been unfruitful. ${ }^{[10,11]}$

In the present study we used data from the population-based Ragusa Cancer Registry to analyze trends in the incidence of pancreatic cancer, as well as the presence and type of familial aggregation of tumors in pancreatic cancer patients. Specific objectives were: to establish the frequency of familial aggregation of tumors and the clinical spectrum of these tumors; to classify and stratify families on the basis of the observed aggregation in order to preselect relatives with cancer for future genetic analysis and thus identify individuals at major risk; and to evaluate survival and possible prognostic factors in familial and sporadic pancreatic cancer patients.

\section{MATERIALS AND METHODS}

The population-based Ragusa Cancer Registry was instituted in 1981. The registry covers a small, homogeneous population in a rural area of southeast Sicily (the province of Ragusa) with 307,697 residents (150,668 men and 157,029 women according to the 2011 census). In the last decade, an average of 1,500 cases of cancer have been recorded in the registry each year, excluding non-melanoma skin cancer. Further details on the specific objectives of the Ragusa Cancer Registry and the main epidemiological data it contains have been previously described. ${ }^{[12,13]}$ From its inception in 1981 through 2009, a total of 966 cases of pancreatic cancer (International Classification of Diseases for Oncology Revision 3 codes C25.0-C25.9) have been recorded (517 men and 449 women).

With the aim to trace a reasonable number of pancreatic cancer patients or their relatives, the analysis on familial aggregation covered the period 2000-2007, during which 384 pancreatic cancer patients (178 men, 206 women) were registered. Pancreatic cancer patients and their relatives were contacted by means of personal General Practitioners (GPs) who facilitated and ethically supported our approach. Most of these GPs were already acquainted with the families and could explain to the patients or their relatives why they were being contacted and elucidate the research aims.

Once contacted, interviews were conducted with pancreatic cancer patients who were alive at the time of the study, or, for deceased patients, the closest family member (husband/wife brother/sister, parent, son/daughter). During the interviews, we administered a specially designed questionnaire to carefully record the main diseases, particularly malignant tumors, occurring in first-, second-, and third-degree relatives. We then used this information to compile a family history of disease, using our original pancreatic cancer patients as probands.

Reported cancers and age of cancer onset in relatives were validated through linkage with the Ragusa Cancer Registry. When linkage was unsuccessful, confirmative clinical notes were sought at GPs' clinics. The clinical diagnoses of probands were reviewed and matched with the clinical course of the disease: benign and borderline tumors were excluded from the analysis; probands that were diagnosed through death certificate only were not excluded as the signing physicians confirmed the underlying cause of death to be pancreatic cancer. Multiple tumors in probands were verified in the same manner.

Probands were categorized according to their family history of cancer as follows: sporadic cases (no other member of the family affected by cancer); simple familial aggregation (at least one first-, second- or third-degree relative with cancer); aspecific verticality (presence of cancer, one of which was usually of the pancreas, in both a parent and his/her child); site-specific verticality (presence of pancreatic cancer in a parent and his/her child).

Written informed consent to participate in the data analysis and possible use of biological material was obtained from all interviewees.

\section{Statistical analysis}

Crude incidence rates $(\times 100,000$ residents $)$ were calculated based on the resident population at various censuses (in Italy, every 10 years). Age-standardized incidence rates were adjusted to the European standard population in 1997. ${ }^{[14]}$ The statistical significance of the difference between sporadic and familial cases was assessed with Student's $t$-test or $\chi$ 
square test as appropriate, with a significance level of $P<$ .05. Analyses of familial aggregation were carried out by presence of familial aggregation (sporadic $v s$. familial cases) and type of familial aggregation (i.e., simple familial aggregation vs. aspecific and site-specific verticality). Differences in pancreatic cancer-specific survival were also analyzed by presence and type of familial aggregation and were assessed with Kaplan-Meier and Log-rank statistics after excluding all cases diagnosed through death certificated only (5 cases). ${ }^{[15]}$
Since breast cancer was the most frequent tumor found in probands' relatives, the median age of relatives suffering from breast cancer was computed.

\section{Results}

Crude and age-standardized incidence rates of pancreatic cancer rose gradually in both sexes, though the increase was more marked among females (see Figure 1).
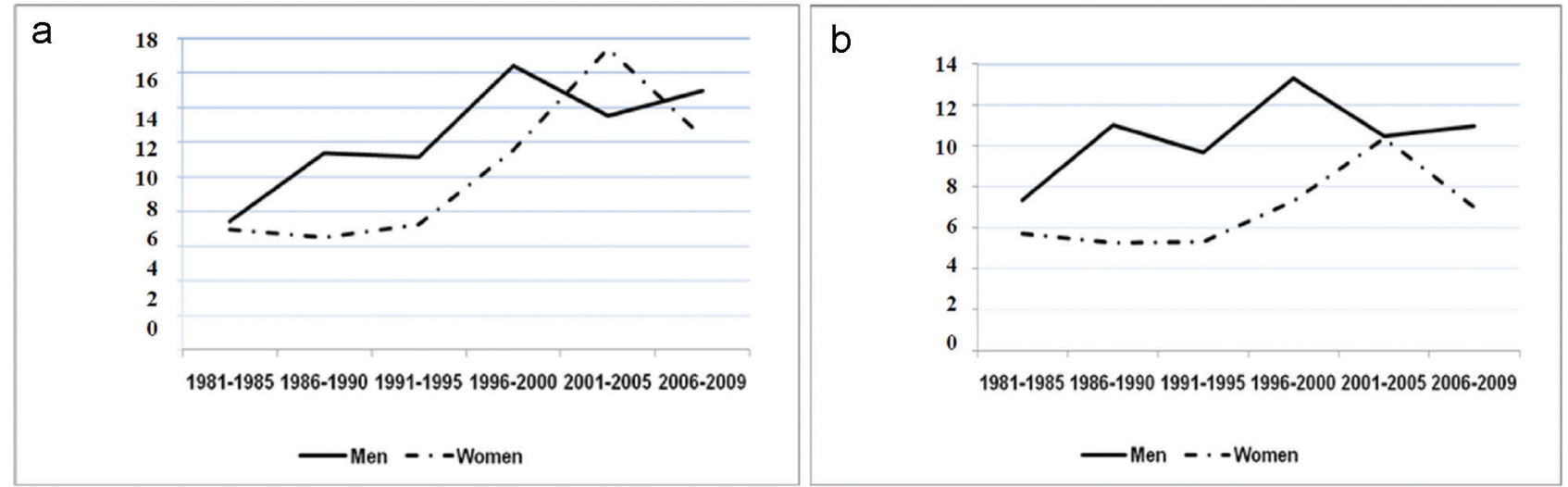

Figure 1. a: Crude incidence rates of pancreatic cancer/100,000 residents in the province of Ragusa, 1981-2009; b: Agestandardized incidence rates of pancreatic cancer/100,000 residents in the province of Ragusa, 1981-2009 (adjusted to the European standard population in 1997)

Only three probands were alive at the time of the interview (two of whom were affected by neuroendocrine pancreatic cancer). The closest relative was contacted for the remaining 139 probands. Forty-seven probands were sporadic cases; 95 probands showed a more or less marked familial aggregation of cancer (67\% of 142). Simple familial aggregation was observed for $43(45.2 \%)$ probands, aspecific verticality for $49(51.6 \%)$, and site-specific verticality for 3 probands $(3.2 \%)$. In a few families, verticality could be assessed in three successive generations. Age at diagnosis of pancreatic cancer among probands was slightly higher in sporadic than in familial cases (see Table 1).

Table 1. Familial and sporadic cases of pancreatic cancer

\begin{tabular}{lllllll}
\hline & Probands (n) & $\begin{array}{l}\text { Age (years) at diagnosis } \\
(\text { mean } \pm \text { SD) }\end{array}$ & $\begin{array}{l}\text { Simple } \\
\text { aggregation }^{\# 1}\end{array}$ & $\begin{array}{c}\text { familial } \\
\text { Aspecific } \\
\text { verticality }^{\# 2}\end{array}$ & $\begin{array}{l}\text { Site-specific } \\
\text { verticality }^{\# 3}\end{array}$ \\
\hline Familial & Male & 56 & $69.6 \pm 12.0$ & 23 & 30 & 3 \\
Cases & Female & 39 & $71.8 \pm 12.0$ & 20 & 19 & 0 \\
$\begin{array}{l}\text { Sporadic } \\
\text { Cases }\end{array}$ & Male & 47 & $73.5 \pm 9.6$ & - & - & \\
Total & Female & & - & 43 & 49 & 3 \\
\hline
\end{tabular}

${ }^{\# 1}$ Presence of cancer in at least one first-, second- or third-degree relative with cancer; ${ }^{\# 2}$ Presence of cancer, one of which was usually of the pancreas, in both a parent and his/her child;

${ }^{\# 3}$ Presence of presence of pancreatic cancer in a parent and his/her child.

Examples of the different types of familial aggregation of cancer are given in Figure 2, Panel A shows a typical case of site-specific verticality, with parent and child both affected by pancreatic cancer at a relatively early age. Rather interestingly in this case, age at cancer occurrence in the son was 12 years earlier than in the father (44 and 56 years, respectively). Panel B shows an example of aspecific verticality; in this large family there were several relatives with cancer, with a striking aspecific verticality in 2 branches, however, the type of cancer was different from one generation to the next. Finally, Panel C shows simple familial aggregation, with several malignancies in the family, but no apparent verticality for pancreatic cancer (see Figures 2, 3). 

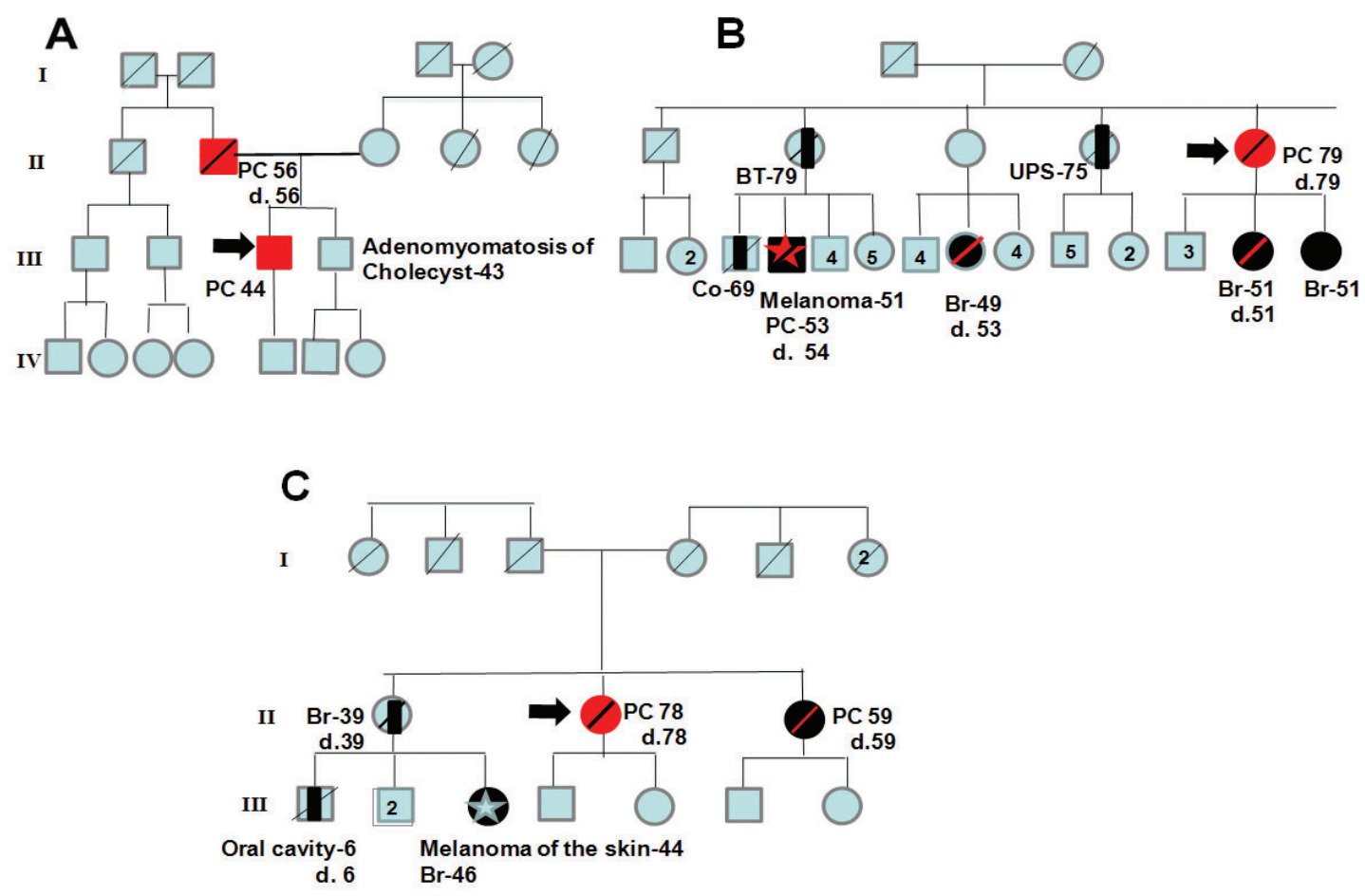

Figure 2. Examples of different types of familial aggregation. A: Site-specific verticality; B: Aspecific verticality; C: Simple familial aggregation

\section{Explanation of symbols}

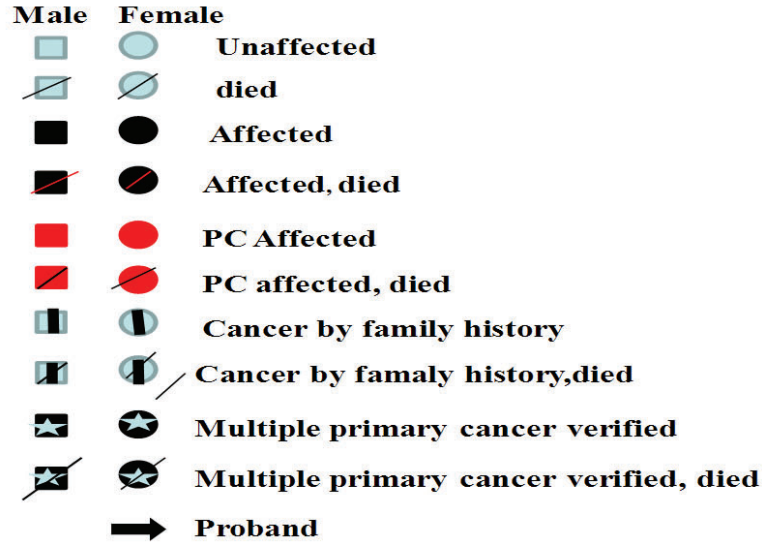

Figure 3. Explanation of symbols in figures

The most frequently reported cancers in the relatives of probands were those of the breast ( 43 cases, $16.5 \%$ of the total), central nervous system (CNS) $(23,8.8 \%)$, stomach (22, $8.4 \%)$, and colon-rectum $(22,8.4 \%)$. Interestingly, a large fraction of these cancers (90 out of 261,34.5\%) occurred before the age of 56 years (see Table 2).

When comparing the clinical and histological data of probands with sporadic and familial pancreatic cancer, the only variable which appeared statistically significant was

$\begin{array}{ll}\text { Cancer site abbreviations } \\ \text { Br } & \text { Breast } \\ \text { Bt } & \text { Brain tumor } \\ \text { Co } & \text { Colon } \\ \text { Melanoma } & \text { Melanoma } \\ \text { Oral cavity } & \text { Oral cavity } \\ \text { PC } & \text { Pancreatic cancer } \\ \text { UPS } & \text { Primary Site Unknown }\end{array}$

mean age at diagnosis, in both sexes. However, in absolute terms the difference was small, and its biological significance rather unclear (see Table 3).

Survival was poor, as expected for pancreatic cancer. Neither stratification by presence of familial aggregation (sporadic $v s$. familial pancreatic cancer) nor type of familial aggregation (simple familial aggregation $v s$. aspecific and site-specific verticality) revealed any appreciable or relevant difference in survival (see Figures 4 and 5). 
Table 2. Neoplasms reported among first-, second-, and third-degree relatives of probands $(\mathrm{n}=261)$ by age group

\begin{tabular}{|c|c|c|c|c|c|c|}
\hline Cancer site & Total & $0-55$ years & 56-71 years & $\geq 71$ years & Unknown age & $\%$ total \\
\hline Breast & 43 & 25 & 5 & 5 & 8 & 16.5 \\
\hline Central Nervous System & 23 & 14 & 4 & 2 & 3 & 8.8 \\
\hline Colon-Rectum & 22 & 2 & 11 & 6 & 3 & 8.4 \\
\hline Stomach & 22 & 4 & 9 & 6 & 3 & 8.4 \\
\hline Leukemia/Lymphoma & 18 & 5 & 7 & 2 & 4 & 6.9 \\
\hline Pancreas & 17 & 8 & 5 & 3 & 1 & 6.5 \\
\hline Liver & 13 & 1 & 3 & 9 & - & 5.0 \\
\hline Prostate & 13 & 1 & 5 & 4 & 3 & 5.0 \\
\hline Lung & 11 & 1 & 5 & 4 & 1 & 4.2 \\
\hline Larynx & 6 & 2 & 2 & 2 & 0 & 2.3 \\
\hline Uterus & 6 & 3 & 1 & 1 & 1 & 2.3 \\
\hline Skin Melanoma & 5 & 4 & 1 & - & - & 1.9 \\
\hline Other sites & 62 & 20 & 20 & 11 & 11 & 23.7 \\
\hline
\end{tabular}

Table 3. Clinical and histological data of patients with sporadic $(\mathrm{n}=47)$ and familial $(\mathrm{n}=95)$ pancreatic cancer

\begin{tabular}{|c|c|c|c|}
\hline $\begin{array}{l}\text { Total cases } \\
(n=142)\end{array}$ & $\begin{array}{l}\text { Sporadic cases } \\
(n=47)\end{array}$ & $\begin{array}{l}\text { Familial cases } \\
(n=95)\end{array}$ & $p$ \\
\hline \multicolumn{4}{|l|}{ Sex } \\
\hline Male & 28 & 56 & .52 \\
\hline Female & 19 & 39 & \\
\hline \multicolumn{4}{|c|}{ Age at diagnosis (years) } \\
\hline$<50$ & 0 & 5 & \\
\hline $50-54$ & 1 & 6 & \\
\hline $55-59$ & 4 & 8 & \\
\hline$\geq 60$ & 42 & 76 & .392 \\
\hline \multicolumn{4}{|c|}{ Mean age $( \pm S D)$} \\
\hline Male & $73.9 \pm 9.4$ & $69.6 \pm 12.0$ & .01 \\
\hline Female & $73.1 \pm 9.2$ & $71.8 \pm 12.0$ & .01 \\
\hline \multicolumn{4}{|c|}{ Histologic diagnosis } \\
\hline Yes & $11(23.4 \%)$ & $33(34.7 \%)$ & .188 \\
\hline No & 36 & 62 & \\
\hline \multicolumn{4}{|l|}{ Stage } \\
\hline Localized & 4 & 8 & .133 \\
\hline Advanced & 20 & 51 & \\
\hline Missing & 33 & 36 & \\
\hline \multicolumn{4}{|c|}{ Multiple primaries } \\
\hline Yes & 6 & 12 & .51 \\
\hline No & 41 & 83 & \\
\hline
\end{tabular}

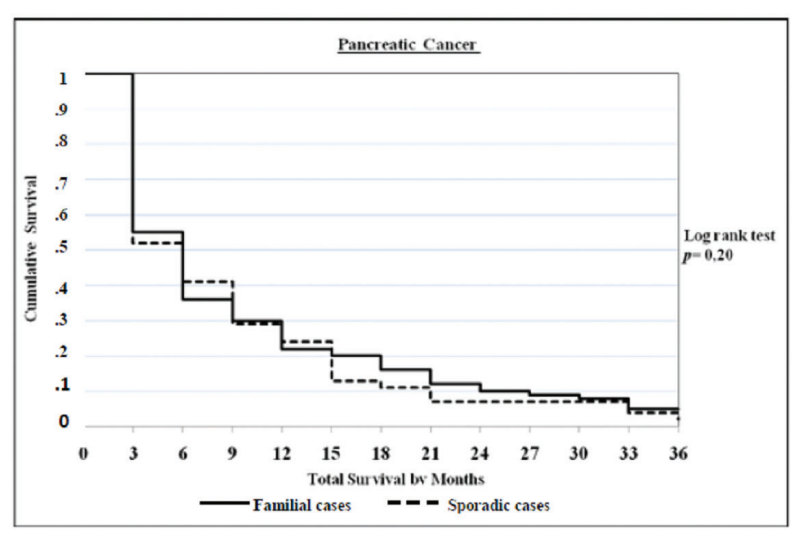

Figure 4. 3-year survival analysis by presence of familial aggregation: sporadic $(\mathrm{n}=47) v s$. familial $(\mathrm{n}=95)$ cases of pancreatic cancer

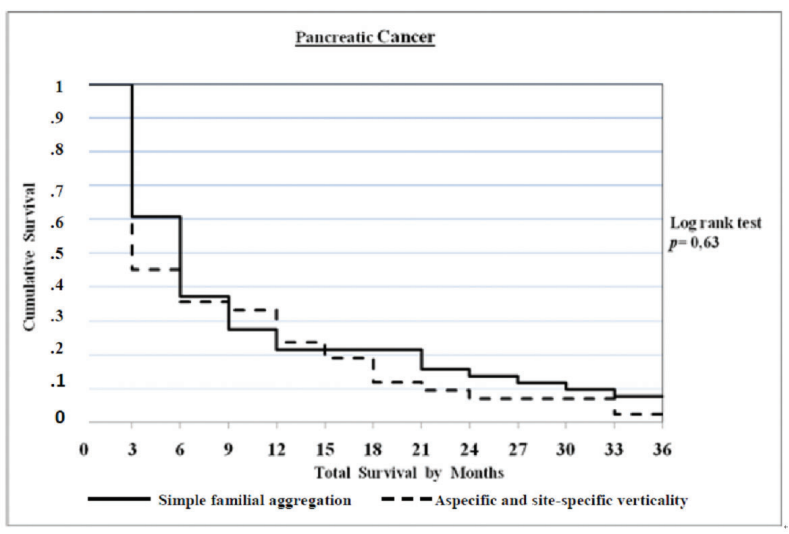

Figure 5. 3-year survival analysis by type of familial aggregation: simple familial aggregation $(\mathrm{n}=43) v s$. aspecific and site-specific verticality $(n=52)$

Finally, Table 4 is an attempt to correlate the familial aggregation we observed with known hereditary syndromes which might involve pancreatic cancer. The attempt could be of interest since it gives an approximate idea of the type of genetic analysis that would be required to properly classify some of the most frequent aggregation of tumors observed in the relatives of our probands. In particular, we focused on 24 (out of 52) families with apparent aspecific and site-specific verticality. Of these, 17 showed a more or less marked aggregation of breast and ovary tumors; in these cases hereditary breast-ovary cancer syndrome could be suspected, which would imply testing for constitutional mutations in the BRCA1 and 2 genes. Three cases could be interpreted as hereditary pancreatic cancer (i.e., the 3 families with site-specific verticality); this syndrome has not been clearly defined in molecular tumors, but several genes - such as CDKN2A, BRCA1 and 2, PALLD and PALB2 - 
could be implicated. Two families were reminiscent of famil- sible role of constitutional mutations of several other genes, ial atypical melanoma multiple male (FAMMM syndrome), including p53 and the mismatch repair machinery.

one of Lynch syndrome and one of Li-Fraumeni syndrome, suspicions which could lead to the investigation of the pos-

Table 4. Type of familial aggregation, hereditary syndrome potentially involved, and corresponding genetic analysis

\begin{tabular}{llll}
\hline Familial aggregation & n & Suspected hereditary syndrome & Relevant genetic tests \\
\hline Aspecific and site-specific verticality & 52 & & \\
Pancreas-Pancreas & 3 & Hereditary pancreatic cancer & CDKN2A, BRCA1, 2, PALL, \\
& & & PALB2 \\
Pancreatic Cancer-Melanoma & 2 & FAMMM & P14- p16 \\
Pancreatic Cancer-Breast-Ovary & 17 & Hereditary breast cancer & BRCA1, 2 \\
Pancreatic Cancer-Colon-rectum & 1 & Lynch syndrome & MSH2, MSH6, MLH1, PMS2 \\
Pancreatic Cancer-Central Nervous System & 1 & Li-Fraumeni & p53 \\
Pancreatic Cancer-Other tumors & 28 & - & - \\
Simple familial aggregation & 43 & - & - \\
Total & 95 & & \\
\hline
\end{tabular}

The median age of relatives with breast cancer diagnosis was 49 years, whereas the median age of females with pancreatic cancer was 75 years.

\section{Discussion}

The present study results showed that the incidence rates of pancreatic cancer increased gradually over the 30 years of registration investigated, with small differences between the sexes. A striking familial aggregation of malignant tumors was found in $67 \%$ of our original pancreatic cancer patients. This aggregation was similar or even higher than that observed for other common neoplasms with a well-grounded hereditary component, such as colorectal and breast cancer, with the added interesting finding that pancreatic cancer onset in children occurred 12 years earlier than in parents suffering from the same malignancy, which is consistent with well-known hereditary cancer syndromes. ${ }^{[16]}$ Finally, we found no differences in observed survival between familial and sporadic pancreatic cancers in our probands. However, these results face challenges of study representativeness and validity of diagnoses.

\subsection{Incidence}

The incidence trend of pancreatic cancer in the province of Ragusa showed a slow, but progressive increase from 6 to 8 cases/100,000/year in 1985-1995 to 12 to 14 cases in 20062009. This increase is similar to that observed in several other Western countries, ${ }^{[17]}$ but it is difficult to explain and interpret. In general terms, it could be speculated that the rising incidence of pancreatic cancer is related to characteristics of a modern lifestyle, such as excessive or unbalanced dietary habits, alcohol intake, low physical activity, depen- dence on diagnostic technology, excessive use of drugs, or an aging of the population, with a possible role of one or several comorbidities, but little more can be said.

\subsection{Familial aggregation}

The most frequent tumor observed in the relatives of probands was breast cancer. This occurrence was not related to mammography screening programs, which were not implemented in the study population during the study period, or to an increasing trend in the incidence of breast cancer. In fact, the latest published data on breast cancer estimated an annual percent change of -1.1, which was not statistically significant during the study period. ${ }^{[18,19]}$ The second most frequent cancer seen in the relatives of probands was cancer of the CNS; however the validity of this finding may be an issue, as 12 of the 23 reported tumors (52\%) were not found in the cancer registry, and thus are based only on information from relatives. Nevertheless, this finding should be further investigated by a specific study on the familial aggregation of patients with CNS malignancies. Other common tumors among the relatives of probands were colorectal and gastric cancers, leukemia/lymphoma, and pancreatic cancer. We assumed that different subgroups of verticality represented different risk categories and hypothesized that some of these categories may allow us to identify the hereditary syndromes responsible for these cancers. Finally, our results on the spectrum of cancers in the relatives of probands are in agreement with previous findings. ${ }^{[20]}$

The present study adds more evidence on the importance of acquiring an accurate and complete family history when carrying out research on pancreatic cancer. Several other investigations tried to analyze familial aggregation of tumors 
in pancreatic cancer patients. Hiripi et al. ${ }^{[21]}$ reported that pancreatic cancer aggregates with several other cancer types in families, suggesting that the presence of pancreatic and breast cancer in many families could be attributed to inherited factors. In 1990, Lynch et al. ${ }^{[22]}$ described the main features of 18 families with a strong aggregation of pancreatic cancer among relatives, estimating that some $6 \%$ of pancreatic cancer patients had a family history of the disease and that this phenomenon could be attributed to an as yet undefined genetic predisposition. More recently, Gargiulo et $a l .{ }^{[23]}$ found that 19 of the 135 pancreatic cancer patients in their study sample could be classified as having suspected Lynch syndrome, and four of these 19 patients had constitutional alterations in the MLH1 or MSH2 genes. Tersmette et al. ${ }^{[24]}$ found a high risk of pancreatic cancer among individuals who have at least 3 first-degree relatives with pancreatic neoplasms. They suggested that these familial aggregates represented a high-risk group suitable for screening and chemoprevention studies. Finally, two recent review articles stressed the importance of familial and hereditary factors in pancreatic cancer patients, although the exact gene (or genes) etiologically associated with the disease has not yet been defined. ${ }^{[25,26]}$ With some obvious differences in our sampling and selection of the study group, our observations are in agreement with the above-mentioned investigations and show a striking aggregation of tumors at various sites - especially breast, CNS, and digestive organs - among the relatives of pancreatic cancer patients. In about $10 \%$ to $20 \%$ of these families, verticality and site-specific association are highly suggestive of hereditary diseases. ${ }^{[27]}$ Moreover, the frequent association between pancreatic cancer and breast cancer occurring before the age of 50-55 years (see Table 2) in our study gives some evidence that germline mutations in BRCA1 and 2 might represent a possible molecular basis, which has also been cited in previous investigations. ${ }^{[28]}$ Similarly, the frequent familial aggregation of colorectal malignancies suggests a possible implication of mutations in DNA mismatch repair genes (mainly MSH2, MLH1 and MSH6), which are associated with the Lynch syndrome phenotype. ${ }^{[29]}$ Other uncommon hereditary syndromes may also be involved, including the still undefined hereditary pancreatic cancer syndrome. ${ }^{[25,26]}$ What is rather clear is that an extensive work-up would be necessary to fully characterize families of pancreatic cancer patients that are suspected to have hereditary pancreatic cancer syndrome, since more than 10 genes could be involved. Indeed, for this reason familial pancreatic cancer might represent a challenge for the new techniques of genome-wide analysis (Next Generation Sequencing). ${ }^{[30]}$

Published by Sciedu Press

\subsection{Survival}

Three-year survival was, as expected, extremely poor, with virtually no difference among the subgroups of presence or type of familial aggregation. Our study may not add significant new knowledge to the current literature, but to the best of our knowledge, our finding that survival did not differ between sporadic and familial pancreatic cancer cases has not been reported in the literature. Moreover, other studies have been based on more selected or restricted study samples, whereas ours was intended to be a population-based approach. Our study did not restrict by clinical variables, compared to the case-series of Singhi et al., ${ }^{[31]}$ where an interesting comparison of histological subtypes is reported, and Barton et al., ${ }^{[32]}$ where Kaplan-Meier analyses were only conducted for surgically resected cases with ductal adenocarcinoma. Once again our data confirm the results of recent studies showing little or no improvement in survival despite apparent early diagnosis and availability of new combination chemotherapy. ${ }^{[33,34]}$ Finally, in line with the above considerations, screening and early diagnosis of pancreatic tumors appear to be unrealistic objectives at present.

\subsection{Study representetiveness}

One of the major strengths of this study was its populationbased approach, with data from the Ragusa Cancer Registry. However, despite this approach, the low traceability of pancreatic cancer patients and/or their families meant that we could only include $37 \%$ of the pancreatic cancer cases diagnosed in 2000-2007. We are aware that including only approximately 1 case out of 3 affects the population representativeness of the study results, but on the other hand the high compliance (only 21 [12.8\%] of the 163 traced patients or relatives refused to participate), the source of our cases (i.e., a convenience sample from a list of patients abstracted from a local population-based cancer registry) and no restrictions based on treatment or histological subtype, allowed us to avoid a simple cases-series or clinical study. ${ }^{[31,32]}$ We assimilated our approach to a questionable population-based survey with limited representativeness. Furthermore, to the best of our knowledge, this study included a larger number of subjects than did other articles in the literature. The high proportion of pancreatic cancer patients that could not be traced $(60 \%)$ was mostly due to the high lethality of pancreatic cancer ${ }^{[20]}$ and GPs' suggestions not to include patients or relatives with severe illnesses for ethical reasons. Furthermore, there was a non-negligible percentage of probands and their relatives that had left the province of Ragusa, and consequently it was not possible to locate them. Only 142 (out of 384: $37 \%$ ) families could be reached and were available to collaborate. 


\subsection{Diagnoses validity}

Another criticism which can be raised is that only was $34.7 \%$ of our probands had a histologic diagnosis of pancreatic cancer, which could introduce another bias. Pancreatic cancer is a tumor with a notoriously low proportion of histological verification. Only $37 \%$ to $65 \%$ of men and $24 \%$ to $61 \%$ of women have such diagnoses recorded in Italian cancer registries. ${ }^{[35]}$ Thus our percentage of histologically verified cases was consistent with those in Italian cancer registries. In addition, we went through clinical notes and supporting documentation: the clinical and diagnostic final reports, treatment information, and the information obtained from GPs were consistent with primary pancreatic cancer in all of the studied cases.

\subsection{Interpretation}

Our results should be interpreted with extreme caution and should be limited to this study setting. We showed that about $30 \%$ of the cases registered in the Ragusa Cancer Registry show a pattern of familiar aggregation of malignancies, which is consistent with other studies; our data probably do not add significant new knowledge and we cannot definitively confirm or rule out the familial factor as a determinant of pancreatic cancer. Despite this cautiousness, we gathered a rather homogeneous study sample, which was more representative of the commonly occurring pancreatic cancer than a surgical or pathological series. Another strength of this study is the use of data from the local cancer registry, which allowed us to verify diagnoses in all probands and in a relevant fraction of neoplasms among probands' relatives. The pedigree analysis and search for the familial aggregation of tumors induced apprehension among relatives and a fully justified need to be not only alerted about, but also in some way protected from the development of pancreatic carcinoma. Al- though any procedure to determine the presence of pancreatic cancer among relatives should be considered (and labelled as) truly optional, we would suggest that family members at risk be followed with endoscopic ultrasound at regular intervals, a technique that should allow a careful examination of the head of the pancreas, ${ }^{[36]}$ with the consequent and possible identification of small lesions to be treated before local invasion or distant metastasis. In addition, or as a possible alternative, these high-risk individuals could be enrolled in chemoprevention studies. ${ }^{[37]}$

\section{Conclusion}

Population-based registries offer basic data to investigate familial cancer risk. They offer a starting point, give tools to generate bio-molecular hypotheses, and contribute to understanding the etiopathogenesis of pancreatic cancer, a rare and lethal tumor. The results of this study are not sufficient to mandate the implementation of genetic counselling; however subdividing and subgrouping patients into different and well-defined categories represent the first step to determine who should undergo genetic testing. Patients with certain familial aggregations (and phenotypes) can be referred to further study of the numerous genes that have been associated with hereditary pancreatic cancer and other tumors such as breast cancer, where a possible role of BRCA1 and 2 gene mutations has been hypothesized in the pathogenesis of some clusters of pancreatic carcinoma.

\section{ACKNOWLEDGEMENTS}

The authors would like to thank the staff of The Ragusa Cancer Registry, the general practitioners of the province of Ragusa, and all of the involved patients and families. The study was supported by the Sicilian Government and AIREONLUS Ragusa, Italy.

\section{REFERENCES}

[1] Warshaw AL, Fernández-del Castillo C. Pancreatic carcinoma. N Engl J Med. 1992; 326 (7): 455-65. PMid:1732772 http://dx.d oi .org/10.1056/NEJM199202133260706

[2] Hidalgo M. Pancreatic cancer. N Engl J Med. 2010; 362(17): $1605-$ 17. PMid:20427809 http://dx.doi.org/10.1056/NEJMra090 1557

[3] Paulson AS1, Tran Cao HS, Tempero MA, et al. Therapeutic advances in pancreatic cancer. Gastroenterology. 2013; 144(6): 131626. PMid:23622141 http://dx.doi.org/10.1053/j.gastro. 2013.01 .078

[4] Verdecchia A, Guzzinati S, Francisci S, et al. Survival trends in European cancer patients diagnosed from 1988 to 1999. EUROCARE Working Group. Eur J Cancer. 2009; 45(6): 1042-66. PMid:19124239 http://dx.doi.org/10.1016/j.ejca.2008.11.029

[5] Black RJ, Bray F, Ferlay J, et al. Cancer incidence and mortality in the European Union: cancer registry data and estimates of national incidence for 1990. Eur J Cancer. 1997; 33(7): 1075-107. http://dx.doi.org/10.1016/S0959-8049(96)00492-3

[6] Edwards BK, Brown ML, Wingo PA, et al. Annual report to the nation on the status of cancer, 1975-2002, featuring population-based trends in cancer treatment. J Natl Cancer Inst. 2005; 97(19): 1407-27. PMid:16204691 http://dx.doi.org/10.1093/jnci/dji289

[7] Ehrenthal D, Haeger L, Griffin $\mathrm{T}$, et al. Familial pancreatic adenocarcinoma in three generations. A case report and a review of the literature. Cancer. 1987; 59(9): 1661-4. http://dx.doi.org/10.1002/1097-0142(19870501)59: 9<1661: : AID-CNCR2820590923>3.0.CO; $2-\mathrm{H}$

[8] Harinck F1, Kluijt I, van der Stoep N, et al. Indication for CDKN2Amutation analysis in familial pancreatic cancer families without melanomas. J Med Genet. 2012; 49(6): 362-5. PMid:22636603 http://dx.doi.org/10.1136/jmedgenet-2011-100563

ISSN 2377-9306 E-ISSN 2377-9330 
[9] Stadler ZK, Salo-Mullen E, Sabbaghian N, et al. Germline PALB2 mutation analysis in breast-pancreas cancer families. J Med Genet. 2011; 48(8): 523-5. PMid:21415078 http://dx.doi .org/10.11 36/jmg. 2010.087379

[10] Rennert G, Bisland-Naggan S, Barnett-Griness O, et al. Clinical outcomes of breast cancer in carriers of BRCA1 and BRCA2 mutations. N Engl J Med. 2007; 357(2): 115-23. PMid:17625123 http://dx.doi.org/10.1056/NEJMoa070608

[11] Lynch HT, Lynch PM, Lanspa SJ, et al. Review of the Lynch syndrome: history, molecular genetics, screening, differential diagnosis, and medicolegal ramifications. Clin Genet. 2009; 76(1): 1-18. PMid:19659756 http://dx.doi .org/10.1111/j.1399-0 $004.2009 .01230 . \mathrm{x}$

[12] Forman D, Bray F, Brewster DH, et al. eds (2014). Cancer Incidence in Five Continents, Lyon, IARC page 752.

[13] AIRTum-Working group (2010). Cancer prevalence in Italy, Italian cancer figures- Report. 2010. Epidemiol Prev. 34: suppl 2.

[14] Graziano G, Bilancia M, Bisceglia L, et al. Statistical analysis of the incidence of some cancers in the province of Taranto 1999-2001. Epidemiol Prev. 2009; 33(1-2): 37-44. PMid:19585874

[15] Cola B, Cuicchi D, Lecce F, et al. Leading Article. Il follow-up intensivo negli operati per cancro colon-rettale. Clinica Chirurgica III, Dipartimento di Scienze Chirurgiche e Anestesiologiche, Università degli Studi di Bologna. Ann. Ital. Chir. 2008; 79: 1-12. PMid:18572732

[16] McFaul CD, Greenhalf W, Earl J, et al. Anticipation in familial pancreatic cancer. European Registry of Hereditary Pancreatitis and Familial Pancreatic Cancer (EUROPAC); German National Case Collection for Familial Pancreatic Cancer (FaPaCa). Gut. 2006; 55(2): 252-8. PMid:15972300 http://dx.doi.org/10.1136/gut.200 5.065045

[17] Søreide K, Aagnes B, Møller B, et al. Epidemiology of pancreatic cancer in Norway: trends in incidence, basis of diagnosis and survival 1965-2007. Scand J Gastroenterol. 2010; 45(1): 8292. PMid:19883280 http://dx.doi.org/10.3109/003655209 03358899

[18] Giorgi D, Giordano L, Piccini P, et al. The National Centre for Screening Monitoring Sixth Report: Mammography screening in Italy: 2005 survey and 2006 preliminary data. Epidemiol Prev. 2008; 32( suppl 1): 7-22. PMid: 18770992

[19] AIRTUM Cancer in Italy, version 2.0. 2015. Available from: http://itacan.ispo.toscana.it/italian/StatsFact.a sp? cancer $=232 \&$ count $r y=3800407$

[20] Wang L, Brune KA, Visvanathan K, et al. 2009 Elevated cancer mortality in the relatives of patients with pancreatic cancer. Cancer Epidemiol Biomarkers Prev. 2009; 18: 2829-34. http: //dx.doi.org/10.1158/1055-9965.EPI-09-0557

[21] Hiripi E, Bermejo JL, Sundquist J, et al. Familial gastrointestinal carcinoid tumours and associated cancers. Ann Oncol. 2009; 20(5): 950-4. PMid:19150948 http://dx.doi.org/10.1093/annonc/ $\operatorname{mdn} 706$

[22] Lynch HT, Fitzsimmons ML, Smyrk TC, et al. Familial pancreatic cancer: clinic-pathologic study of 18 nuclear families. Am J Gastroenterol. 1990; 85(1): 54-60. PMid:2296965

[23] Gargiulo S, Torrini M, Ollila S, et al. Germline MLH1 and MSH2 mutations in Italian pancreatic cancer patients with suspected Lynch syndrome. Fam Cancer. 2009; 8(4): 547-53. PMid:19728162 http: //dx.doi.org/10.1007/s10689-009-9285-1

[24] Tersmette AC, Petersen GM, Offerhaus GJ, et al. Increased risk of incident pancreatic cancer among first-degree relatives of patients with familial pancreatic cancer. Clin Cancer Res. 2001; 7(3): 738-44. PMid:11297271

[25] Jørgensen MT, Mortensen MB, Gerdes AM, et al. Familial pancreatic cancer. Scand J Gastroenterol. 2008; 43(4): 387-97. PMid:18365902 http://dx.doi.org/10.1080/00365520701775229

[26] Grover S, Syngal S. Hereditary pancreatic cancer. Gastroenterology. 2010; 139(4): 1076-80, 1080.e1-2.

[27] Lynch HT, Smyrk T, Kern SE, et al. Familial pancreatic cancer: a review. Semin Oncol. 1996; 23(2): 251-75. PMid:8623061

[28] Greer JB, Whitcomb DC. Role of BRCA1 and BRCA2 mutations in pancreatic cancer. Gut. 2007; 56(5): 601-5. PMid:16973716 http://dx.doi.org/10.1136/gut.2006.101220

[29] Lynch HT, Lynch JF, Lynch PM, et al. Hereditary colorectal cancer syndromes: molecular genetics, genetic counseling, diagnosis and management. Fam Cancer. 2008; 7(1): 27-39. PMid:17999161 http://dx.doi.org/10.1007/s10689-007-9165-5

[30] Yang Y, Muzny DM, Reid JG, et al. Clinical whole-exome sequencing for the diagnosis of mendelian disorders. N Engl J Med. 2013; 369(16): 1502-11. PMid:24088041 http://dx.doi.org/10.10 56/NEJMoa1306555

[31] Singhi AD, Ishida H, Ali SZ, et al. A histomorphologic comparison of familial and sporadic pancreatic cancers. Pancreatology. 2011; 15(4): 387-91. PMid:25959245 http://dx.doi .org/10.1016/j .pan.2015.04.003

[32] Barton JG, Schnelldorfer T, Lohse CM, et al. Patterns of pancreatic resection differ between patients with familial and sporadic pancreatic cancer. J Gastrointest Surg. 2015; 15: 836-42. PMid:21359597 http://dx.doi.org/10.1007/s11605-011-1417-x

[33] Neoptolemos JP, Stocken DD, Bassi C, et al. European Study Group for Pancreatic Cancer. Adjuvant chemotherapy with fluorouracil plus folinic acid vs gemcitabine following pancreatic cancer resection: a randomized controlled trial. JAMA. 2010; 304(10): 107381. PMid:20823433 http://dx.doi.org/10.1001/jama. 2010 .1275

[34] Conroy T, Desseigne F, Ychou M, et al. Groupe Tumeurs Digestives of Unicancer; PRODIGE Intergroup. FOLFIRINOX versus gemcitabine for metastatic pancreatic cancer. N Engl J Med. 2011; 364(19): 1817-25. PMid:21561347 http://dx.doi .org/10.1056/NEJMo a1011923

[35] Forman D, Bray F, Brewster DH, et al. Indices of data quality in Cancer Incidence in Five Continents. 2014: 1282-1283. Available from: http://www.iarc.fr/en/publications/pdfs-o nline/epi/sp164/CI5volX-16.pdf

[36] Langer P, Kann PH, Fendrich V, et al. Five years of prospective screening of high-risk individuals from families with familial pancreatic cancer. Gut. 2009; 58(10): 1410-8. PMid:19470496 http://dx.doi.org/10.1136/gut.2008.171611

[37] Hawk ET, Umar A, Viner JL. Colorectal cancer chemopreventionan overview of the science. Gastroenterology. 2004; 126(5): 142347. PMid:15131803 http://dx.doi.org/10.1053/j.gastro. 2004.03 .002 